\title{
Crystal Structure of Dicalcium Cuprate, $\mathrm{Ca}_{2} \mathrm{CuO}_{3}$
}

\author{
Michael Hjorth ${ }^{\mathrm{a}}$ and Jens Hyldtoft ${ }^{\mathrm{b}, *}$

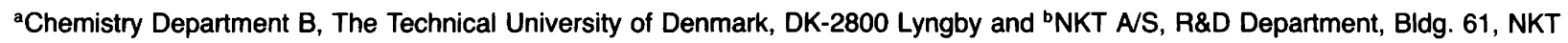 \\ Allé 1, DK-2605 Brøndby, Denmark
}

Hjorth, M. and Hyldtoft, J., 1990. Crystal Structure of Dicalcium Cuprate, $\mathrm{Ca}_{2} \mathrm{CuO}_{3}$. - Acta Chem. Scand. 44: 516-518.

When one attempts to prepare superconducting bismuth calcium copper oxides ${ }^{1}$ using solid-state synthesis, various other oxides occur among the reaction products, e.g. dicalcium cuprate. ${ }^{2}$ The structure of $\mathrm{Ca}_{2} \mathrm{CuO}_{3}$ was reported by Teske and Müller-Buschbaum, ${ }^{3}$ who characterized the structure from a very small data set (86 reflections). When characterizing the reaction products from solid-state syntheses, a good knowledge of possible reaction products is important; thus it was considered worthwhile to refine the structure from a larger data set.

In the present work, the structure was refined from single-crystal X-ray diffraction data collected on an automatic four-circle diffractometer, and microcrystals from the sample were examined using high-resolution transmission electron microscopy (HRTEM) and selected-area electron diffraction (SAED). The electron microscopy study provides information on defects in the crystals, thus contributing to a better understanding of metal oxide structures.

Energy-dispersive X-ray analysis (EDX) indicated significant amounts of strontium and traces of bismuth, as also seen in Ref. 2, and thus the X-ray investigation was carried out with both calcium and strontium on the calcium site, giving the composition $\mathrm{Ca}_{1.82} \mathrm{Sr}_{0.18} \mathrm{CuO}_{3}$.

\section{Experimental}

Golden needle-shaped single crystals of dicalcium cuprate were found when attempting to prepare one of the superconducting phases in the newly discovered $\mathrm{Bi}$-system ${ }^{1}$ by the following procedure.

A grey powder was obtained by dissolving the nitrates of $\mathrm{Bi}, \mathrm{Sr}, \mathrm{Ca}$ and $\mathrm{Cu}$ in ethylene glycol with a molar ratio $4: 3: 3: 4$, adding citric acid, and by a slow heating to $800^{\circ} \mathrm{C}$ to decompose the nitrates..$^{4.5}$ The powder was pressed to a pellet and sintered in air for $40 \mathrm{~h}$ at $860^{\circ} \mathrm{C}$.

The crystals appeared on the surface of the pellet and could easily be removed from the sample.

Single-crystal X-ray data were collected with an EnrafNonius CAD4 diffractometer, and were corrected for background, Lorentz, polarization and absorption effects. Sta-

\footnotetext{
* Present address: Haldor Topsøe A/S, Nymøllevej 55, DK-2800 Lyngby, Denmark.
}

tistical analysis of psi-scans of eight different reflections were used to check the crystal dimensions used for absorption correction. A summary of the experimental conditions is given in Table 1. Systematic absences indicated an Icentred space group, and the space group Immm is sup-

Table 1. Crystal data and experimental conditions.

\begin{tabular}{|c|c|}
\hline $\begin{array}{l}\text { Formula } \\
\text { Formula weight } \\
\text { Space group } \\
\text { Unit cell/§ }\end{array}$ & $\begin{array}{l}\mathrm{Ca}_{1.821(5)} \mathrm{Sr}_{0.179(5)} \mathrm{CuO}_{3} \\
200.2 \\
\text { Immm } \\
a=3.2781(4), b=3.7870(4), \\
c=12.277(1)\end{array}$ \\
\hline Unit cell volume $/ \AA^{3}$ & $152.40(5)$ \\
\hline Formula units per unit cell & 2 \\
\hline Calculated density $/ \mathrm{g} \mathrm{cm}^{-3}$ & $4.363(1)$ \\
\hline Radiation & MoKa \\
\hline Wavelength $/ \AA$ & 0.71073 \\
\hline Temperature/K & $293(1)$ \\
\hline Crystal shape & Prismatic \\
\hline Crystal size/mm & $0.024 \times 0.194 \times 0.070$ \\
\hline Diffractometer & Enraf-Nonius CAD4 \\
\hline \multicolumn{2}{|l|}{ Determination of unit cell: } \\
\hline Number of reflections used & 24 \\
\hline$\theta$-range $/^{\circ}$ & 9.98 to 14.77 \\
\hline \multicolumn{2}{|l|}{ Intensity data collection: } \\
\hline Maximum $\sin \theta / N / \AA^{-1}$ & 1.08 \\
\hline Range of $h, k$ and $I$ & 0 to $7 ;-8$ to $8 ; 0$ to 26 \\
\hline Standard reflections & $0 \overline{2} 0,116$ and 123 \\
\hline Intensity instability & Insignificant $\Delta /<3 \sigma(\eta)$ \\
\hline No. of collected reflections & 973 \\
\hline No. of unique reflections & 492 \\
\hline No. of observed reflections & 373 \\
\hline Criterion for significance & $1>3 \sigma(n)$ \\
\hline Internal $R$ & 0.017 \\
\hline \multicolumn{2}{|l|}{ Absorption correction: } \\
\hline $\begin{array}{l}\text { Linear absorption } \\
\text { coefficient } / \mathrm{cm}^{-1}\end{array}$ & 102.7 \\
\hline Transmission factor range & $0.45-0.77$ \\
\hline \multicolumn{2}{|l|}{ Structure refinement: } \\
\hline Minimization of & Sum of $w(\Delta F)^{2}$ \\
\hline Anisotropic model for & All atoms \\
\hline $\begin{array}{l}\text { Number of refined } \\
\text { parameters }\end{array}$ & 17 \\
\hline Extinction parameter & $8(1) \times 10^{2}$ \\
\hline Maximum correction & 1.12 \\
\hline Weighting scheme & $\left(\sigma_{F}^{2}+0.0001 F^{2}\right)^{-1}$ \\
\hline Final $R$ & 0.019 \\
\hline Final $R_{w}$ & 0.022 \\
\hline
\end{tabular}


Table 2. Fractional coordinates and thermal parameters for $\mathrm{Ca}_{2} \mathrm{CuO}_{3}$ with estimated standard deviations in parentheses.

\begin{tabular}{lllll}
\hline Atom & $x$ & $y$ & $z$ & $U_{\text {eq }}{ }^{a}$ \\
\hline $\mathrm{Ca}$ & $\frac{1}{2}$ & 0 & $0.15016(3)$ & $0.0061(1)$ \\
$\mathrm{Cu}$ & 0 & $\frac{1}{2}$ & 0 & $0.0051(1)$ \\
$\mathrm{O} 1$ & $\frac{1}{2}$ & 0 & $0.3402(1)$ & $0.0080(4)$ \\
$\mathrm{O} 2$ & 0 & 0 & 0 & $0.0081(6)$ \\
\hline
\end{tabular}

${ }^{a} U_{e q}=\frac{1}{6 \pi^{2}} \sum \beta_{i j} a_{i} a_{j}$.

ported by the outcome of the refinement, thus verifying the space group of Ref. 3 .

The structure was refined using the coordinates of Teske and Müller-Buschbaum ${ }^{3}$ as a starting point. The calculations were carried out with the least-squares program UP$\mathrm{ALS}^{6}$ including an isotropic type I extinction parameter, and the crystal showed only very small extinction effects (cf. Table 1). Scattering factors for neutral atoms were taken from Ref. 8. Final atomic coordinates and thermal parameters are listed in Table 2. Listings of observed and calculated structure factors as well as anisotropic temperature factors are available from the authors on request.

For the electron micrographs, SAED images and EDX analyses, a $400 \mathrm{kV}$ Jeol JEM $4000 \mathrm{EX}$ microscope with a resolving power of approximately $1.4 \AA$, and a $300 \mathrm{kV}$ Philips EM430 instrument with resolving power of approximately $2.3 \AA$, have been used.

\section{Discussion}

The structure of $\mathrm{Ca}_{2} \mathrm{CuO}_{3}$ can be considered as built of edge-sharing oxygen coordination polyhedra; calcium is seven-coordinated in a monocapped trigonal prism and copper is four-coordinated in a distorted square plane. The trigonal prisms share triangular faces in the $a$ direction and edges in the $b$ direction to build a layer of equally orientated calcium polyhedra. Two of the calcium layers, related by a mirror plane, share the free edge of the trigonal prism, giving double layers in which there are tunnels where the copper atoms are placed. This sandwich is then stacked along the $c$ axis to give the three-dimensional structure (Fig. 1). The bond lengths in the coordination polyhedra are given in Table 3, and are close to those of Ref. 3. The

Table 3. Bond distances and multiplicities in the coordination polyhedra of $\mathrm{Ca}_{2} \mathrm{CuO}_{3}$.

\begin{tabular}{lll}
\hline Bond & Distance & Multiplicity \\
\hline $\mathrm{Ca}-\mathrm{O} 1$ & $2.3336(14) \AA$ & - \\
$\mathrm{Ca}-\mathrm{O} 2$ & $2.4667(3) \AA$ & $2 \times$ \\
$\mathrm{Ca}-\mathrm{O} 1$ & $2.5071(2) \AA$ & $4 \times$ \\
$\mathrm{Cu}-\mathrm{O} 2$ & $1.8935(2) \AA$ & $2 \times$ \\
$\mathrm{Cu}-\mathrm{O} 1$ & $1.9613(14) \AA$ & $2 \times$ \\
\hline
\end{tabular}

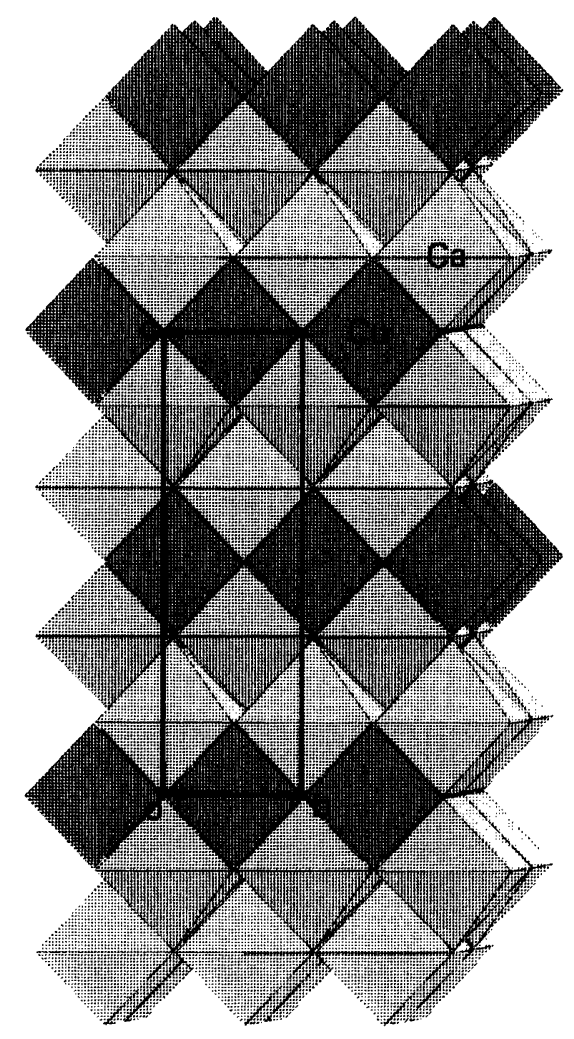

Fig. 1. Polyhedral plot ${ }^{12}$ of $\mathrm{Ca}_{2} \mathrm{CuO}_{3}$ with the $b$ axis horizontal and $c$ axis vertical. The plot is slightly rotated to visualize the packing along the $a$ axis.

strontium refines to occupy $9.0(3) \%$ of the calcium position.

Empirical bond-valences have been estimated using the functions and parameters of Brown and Altermatt, ${ }^{9}$ in order to compare the metal-oxygen bond distance distribution with that observed in other metal oxide structures. The values obtained are 2.03 for copper and 1.83 for calcium; thus copper has a coordination in agreement with that observed in the structures from which Brown and Altermatt derived their parameters, whereas calcium has longer bonds than expected from this approach. The discrepancy concerning calcium may be ascribed to the large coordination number of the small $\mathrm{Ca}^{2+}$ ion. When calculating the bond-valence parameter for $\mathrm{Sr}^{2+}$ in the isotypic compound $\mathrm{Sr}_{2} \mathrm{CuO}_{3},{ }^{10}$ the value 1.98 is obtained, indicating that the $\mathrm{Sr}^{2+}$ ion suits the seven-coordination better than the $\mathrm{Ca}^{2+}$ ion when applying these bond-valence parameters. Discrepancies of this type have often been seen when calculating bond-valence parameters for unusual coordinations of metal ions (e.g. Ref. 11).

In Fig. 2 the electron micrograph and electron diffraction patterns are seen, and it is noted that the high-resolution image [Fig. 2(a)] shows no defects, except for a thin disordered layer at the surface. Selected-area electron diffraction images [Figs. 2(b) and (c)] are very sensitive to local defects; thus, as no streaks or superlattice spots are ob- 



Fig. 2. Electron micrograph and selected-area diffraction (SAED) patterns of $\mathrm{Ca}_{2} \mathrm{CuO}_{3}$. The electron micrograph (a) is taken with the beam parallel to the $\left[\begin{array}{ll}0 & 1\end{array}\right]$ ] direction and shows no defects except for a thin disordered surface layer [corresponding SAED in (b)]. The SAED patterns [(b) and (c)] show no streaks or superlattice spots, thus indicating no local defects in the selected crystals.

served, it is concluded that the crystals examined are homogeneous with very few defects. On this basis it may be expected that the crystals in general are well ordered; this is consistent with the $\mathrm{X}$-ray refinement, which gives reasonable values of all thermal parameters.
Acknowledgements. The staff at the National Center for HREM, University of Lund, Sweden are acknowledged for giving access to the Jeol JEM 4000EX microscope and for practical assistance. M.H. is indebted to the Otto Mønsted Foundation for financial support during his stay in Lund. The availability of the Philips EM430 microscope was made possible through grants from the Danish Research Councils, SNF and STVF.

\section{References}

1. Maeda, H., Tanaka, Y., Fukutomi, M. and Asano, T. Jpn J. Appl. Phys. 27 (1988) L209.

2. Hazen, R. M., Prewitt, C. T., Angel, R. J., Ross, N. L., Finger, L. W., Hadidiacos, C. G., Veblen, D. R., Heaney, P. J., Hor, P. H., Meng, R.L., Sun, Y.Y., Wang, Y.Q., Xue, Y. Y., Huang, Z. J., Gao, L., Bechtold, J. and Chu, C.W. Phys. Rev. Lett. 60 (1988) 1174.

3. Teske, C. L. and Müller-Buschbaum, H. Z. Anorg. Allg. Chem. 379 (1970) 234.

4. Marcilly, C., Courty, P. and Delmon, B. J. Am. Ceram. Soc. 53 (1970) 56.

5. Wang, H. H., Carlson, K. D., Geiser, U., Thorn, R. J., Kao, H.-C. I., Beno, M. A., Monaghan, M.R., Allen, T. J., Proksch, R. B., Stupka, D. L., Williams, J. M., Flandermeyer, B. K. and Poeppel, R. B. Inorg. Chem. 26 (1987) 1474.

6. Lundgren, J.-O. Crystallographic Computer Programs. Report UUIC-B13-4-06D. University of Uppsala, Uppsala 1985.

7. Becker, P. J. and Coppens, P. Acta Crystallogr., Sect. A 30 (1974) 129.

8. International Tables for X-Ray Crystallography, Kynoch Press, Birmingham 1974, Vol. IV.

9. Brown, I. D. and Altermatt, D. Acta Crystallogr., Sect. B 41 (1985) 244.

10. Teske, C. L. and Müller-Buschbaum, H. Z. Anorg. Allg. Chem. 371 (1969) 325.

11. Hjorth, M. Acta Chem. Scand., Ser. A 42 (1988) 727.

12. Norrestam, R. Acta Crystallogr., Sect. A 40 (1984) C-438.

Received November 15, 1989. 